\title{
ARTICLES
}

\section{PHYLOGENETIC DIVERSITY OF SOME SMALL MAMMALS FROM SCIURUDAE FAMILY IN MONGOLIA}

\author{
Bolortuya U. ${ }^{2}$, Bayarmaa G. ${ }^{1}$, Hamit A. ${ }^{1}$, Mandakhtsetsen Kh. ${ }^{3}$, Oyuntsetseg D. ${ }^{1}$ and Bayarlkhagva D. ${ }^{1 \text { * }}$ \\ ${ }^{I}$ Department of Biology, School of Arts and Sciences, National University of Mongolia, \\ Ulaanbaatar, Mongolia \\ ${ }^{2}$ Institute of General and Experimental Biology, Mongolian Academy of Sciences, \\ Ulaanbaatar, Mongolia \\ ${ }^{3}$ Biotechnology and Innovation Department, National Center for Public Health, \\ Ulaanbaatar, Mongolia
}

\begin{abstract}
The squirrel family, Sciuridae, is one of the largest and widespread, ecologically common families of mammals. Due to the conspicuousness of this small mammal group with a big population, insufficient knowledge exists about its phylogenetic relationships. In this study, we identified 14 DNA sequences of mitochondrial cytochrome oxidase I gene in 6 species of Sciuridae and these sequences were compared with corresponding published COI gene sequences of the same species in Eurasia and determined their phylogenetic relationships by Neighbor-joining method.
\end{abstract}

Keywords: Phylogeny; Sciuridae; mtDNA; cytochrome oxidase I;

\section{INTRODUCTION}

The squirrel family, Sciuridae, is a large, attentively studied group of mammals. The family consists of more than 273 species in 50 genera and found on all mainlands except Australia and the Antarctica. The behavior, ecology, morphology and molecular biology of this widespread and diversified group of species have been studied on a large scale. Sciuridae live in almost every habitat from tropical rainforest to semiarid desert.

DNA sequence-based taxonomic approach is widely used in molecular phylogeny for determining its relationship pattern and identifying its relationship to a particular species [1, 9]. Morphological and other quantitative examination is not adequately efficient to distinguish all the species, especially among individuals from the same population and among distantly related species. Combining with a reliable DNA analysis, it can be an efficient pattern for phylogeny. The population structure and genetic distinctiveness of a population also can be determined by genetic distances.

Based on the existence of conserved and less conserved regions within the same molecule and the relatively elevated mutation rate, mtDNA serves as a biomarker in phylogenetic

*corresponding author: bayarlkhagva@num.edu.mn

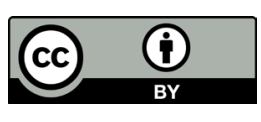

The Author(s). 2018 Open access This article is distributed under the terms of the Creative Commons Attribution 4.0 International License (https://creativecommons.org/licenses/by/4.0/), which permits unrestricted use, distribution, and reproduction in any medium, provided you give appropriate credit to the original author(s) and the source, provide a link to the Creative Commons license, and indicate if changes were made. 
studies for comparisons [7]. The mitochondrial cytochrome oxidase I (COI or COXI) gene is broadly used in phylogenetic studies to resolve divergences of interspecific relationships, the intraspecific situations of population subdivisions and the genetic differentiation beyond the resolving ability of non-molecular approaches [3].

Phylogenetic dependence of Mongolian small

\section{MATERIALS AND METHODS}

Specimens consisted with 14 representatives of 6 species in Sciuridae family and samples collected from 7 locations in north-western Mongolia. Total DNA was extracted from muscle samples with a genomic DNA extraction kit (DNeasy Blood \& Tissue (QIAGEN)). The COI gene was amplified by LCO-1490 (F: 5'-GGTCAACAAATCATAAAGATATTGG -3') and HCO-2198 (R: 5'-TAAACTTCAGGG TGACCAAAAAATCA-3') primers. PCR mix consisted of $100 \mathrm{mg}$ of genomic DNA, $1.0 \mu \mathrm{M}$ of each forward and reverse primers, $200 \mu \mathrm{M}$ of dNTP and 1.25 units of Taqpolymerase (rTaq: Takara, Japan). PCR cycling condition was 3 min denaturation at $94^{\circ} \mathrm{C}, 30$ cycles of 30 sec denaturation at $94^{\circ} \mathrm{C}, 30 \mathrm{sec}$ annealing at $50^{\circ} \mathrm{C}, 1 \mathrm{~min}$ extension at $72^{\circ} \mathrm{C}$ and $2 \mathrm{~min}$ final extension at $72^{\circ} \mathrm{C}$.

Cycle sequencing was conducted by Big Dye Terminator V1.1 sequencing kit. Reaction was prepared in $10 \mu \mathrm{L}$ with $3.4 \mu \mathrm{LH}_{2} \mathrm{O}, 4.0 \mu \mathrm{L}$ BigDye Mix, $1.6 \mu \mathrm{M}$ primer, $1 \mu \mathrm{L}$ of PCR product and cycle sequencing condition was 25 cycles of $1 \mathrm{~min}$ at $96^{\circ} \mathrm{C}, 10 \mathrm{sec}$ at $96^{\circ} \mathrm{C}, 5 \mathrm{sec}$ at $50^{\circ} \mathrm{C}, 4 \mathrm{~min}$ at $60^{\circ} \mathrm{C}$. Nucleotide sequencing was carried out applying the Beckman Coulter protocol.

To complement our analysis, all the comparable

\section{RESULTS}

In this study, we defined the partial sequences of COI gene in 14 representatives of 6 species in Sciuridae family including marmot, ground squirrel, chipmunk and red squirrel. Sequence data submitted in NCBI database is mammals, belonging to the squirrel family, based on molecular marker sequences, has been less studied in the country. In order to identify their species-level history of evolution, we defined partial sequencing of COI gene from 14 representatives of 6 species in four genus in Mongolia and compared with the matching sequences in Sciuridae, that could be obtained from GenBank.

additional sequences were obtained from the NCBI GeneBank database. The sequences identified in this study (KU527904 and KX859265 for Sciurus vulgaris, KU527905, KU527906 and KX859266 for Tamias sibiricus, KU527907, KX859256, KX859257 and KU527908 for Urocitellus undulatus, KX859270 for Spermophiluspallidcauda Brandt, KX859254, KU527909 and KX859268 for Marmota sibirica, KX859255 for Marmotabaibacina) compared with corresponding COI gene sequences from GenBank (JF499341 for Sciurus vulgaris, JF444471, KM537944 and JQ599843 for Tamias sibiricus, KM537985 for Urocitellus ungulates, KJ466738 for Marmota sibirica) for the family of Sciuridae (Sciurus, Eutamias, Spermophilus, and Marmota). Phylogenetic tree re-rooted with Graphirus kelleni of Gliridae family (most closely related to Sciuridae) as an outgroup. The evolutionary history inferred using the Neighbor-Joining method [8]. The evolutionary distances were computed using the Maximum Composite Likelihood method [10]. Evolutionary analyses were conducted in MEGA7 with 1000 bootstrapped replications [6].

shown in table 1. Neighbor joining tree with 20 cytochrome oxidase I gene sequences of Sciuridae family from 6 species of Eurasia and with a representative of most closely related Gliridae family as an outgroup is shown in 
Figure 1. Four clades detected corresponding to four genus of Sciuridae family: each clade consists of only marmots, ground squirrel, chipmunk and red squirrel.

Chipmunk samples were collected from Khuvsgul and Selenge aimags respectively. COI gene sequence data from our samples compared with that of Tamias sibiricus from China and Russia. Data analysis indicated that samples from Khuvsgul (KU527906.1) and northern Selenge (KU527905.1) aimags clustered in the same block, and genetic distance showed that these populations are identical, while that from southern Selenge (KX859266.1) aimag closely related with the Russian individual (KM537944.1, JQ599843.1). Tamias sibiricus from China (JF444471.1) was comparatively distinct from the below individuals with 1.0 genetic distance (Fig. 1A, clade A).

Marmots are large groups in the genus marmota with 14 species in the world, including 2 species of marmots (Marmota sibirica and Marmota baibacina) registered in Mongolia. The number of Marmota sibirica (grey marmot) has decreased drastically in recent years due to aggressive hunting and is now considered an endangered species [12]. In our study, samples were collected from three different populations of Marmota sibirica inhabiting the distant places of Mongolia (Tosontsengel and Dörvöljin soums in Zavkhan aimag, Tsagaanuul soum in Khuvsgul aimag) and samples of Marmota baibacina (Altai marmot) taken from Bulgan, Bayan-Ulgii aimags respectively. Identified nucleotide sequences of these four individuals compared with the sequence data of Inner Mongolian grey marmot (KJ466738.1), which is registered in NCBI database by the neighbor joining method. Results indicated that the grey marmots in Outer (KX859254.1, KX859268.1, KU527909.1) and Inner Mongolia were identical in their sequences and formed a clade consisting of only grey marmots. However, Altai marmot (KX859255.1) are separate from the grey marmots, confirming that these two species of marmots are registered in Mongolia (Fig. 1A, clade B).

We have four species of ground squirrel (Spermophilus and Urocitellus) in Mongolia. COI gene sequences were identified from two of them such as Spermophillu spallidicauda and Urocitellus undulates at four different locations in Khovd and Zavkhan aimags. Nucleotide sequences of these individuals were analyzed with additional GenBank sequences of Spermophillus from Russia. As a result, DNA sequences of samples from Khovd (KU527907.1) and Zavkhan (KU527908.1) were identical with that of the Russian data (KM537985.1), while the sequences of two other samples (KX859256.1 and KX859257.1) from the same places in Khovd aimag were similar to each other, indicating there is no difference in genetic divergence between the populations (Fig. 1A, clade C). However, average distances within these two blocks by Tamura-Nei revealed that they are far diverged species. A little difference within the nucleotide sequences could not appear in Fig. 1A, when the tree was re-rooted with the outgroup. Thus, in order to show that there were differences in spermophilus and urocitellus, phylogenetic tree was constructed only with the ground squirrel species (Fig. 1B). COI gene sequence of Spermophillus pallidicauda was not found in the NCBI database except our data.

There is only a species of Sciurus vulgaris (red squirrel) in Mongolia. Its main habitat is in the forested area of northern Mongolia. Samples were collected from three different aimags of Zavkhan, Selenge and BayanUlgii respectively. The genetic distance of the three samples taken from the spatially separated populations showed that these populations (KU527904.1, JF499341.1, KX859265.1) are genetically identical (Fig. 1 , clade D). Consequently, we expect that the persistence time for populations is much shorter in the samples collected regions and have not accumulated nucleotide differences in cytochrome oxidase I gene sequence. 


\section{DISCUSSION}

This group of small mammals is broadly spread through our country. However, they are comparatively less studied and are least known than the large mammals in Mongolia. We identified the partial sequence of COI gene from 6 species of Sciuridae family and registered then in the NCBI database. Comparison of our data with affiliated sequences in database indicated genetic distances and phylogeny of the populations.

The phylogeny of species in Rodentia of Mongolia is not well researched. Taxonomic study of the Siberian chipmunk (Tamias sibiricus) of Mongolia, Korea, China and Russia were carried out by comparing nuclear DNA c-myc exon 2 and mtDNA control region sequences [4]. The nucleotide sequences of cytb gene of $S$. alashanicus of Mongolia was compared with127 sequences of other Spermophilus species form GenBank and it was found that $S$. alashanicus and $S$. dauricus have close phylogenetic relationship [2].

Species of Spermophilus genus and marmot are well known for their high level of hybridization in the nature [2]. Earlier, Russian researchers performed studies to identify such hybridized individuals by karyological and RAPD PCR analysis in the overlapping zone of pallid ( $S$. pallidicauda) and alashan ( $S$. alaschanicus) ground squirrels in Mongolia [5, 11]. Such interspecies hybridization can be effective in the reconstruction of phylogeny. Since hybridized individuals are still originating in the nature, it is possible to distinguish them by a most reliable method of sequencing COI gene, based on potential internal resources. Our registered sequences of Sciuridae, Rodentia in NCBI GeneBank would be useful for biodiversity assessment to identity unknown samples of species.

Table 1. Registration number for partial sequences of COI gene in small mammals in NCBI (GenBank accession numbers)

\begin{tabular}{|l|l|l|l|}
\hline \multicolumn{1}{|c|}{ Code } & Scientific name of the species & \multicolumn{1}{|c|}{$\begin{array}{c}\text { Local name of the } \\
\text { species }\end{array}$} & $\begin{array}{c}\text { Registration } \\
\text { number }\end{array}$ \\
\hline MGL-16 & Sciurus vulgaris, Linnaeus., 1758 & Baraan kherem & KU527904 \\
\hline MGL-87 & Sciurus vulgaris, Linnaeus., 1758 & Baraan kherem & KX859265 \\
\hline MGL-17 & Tamias sibiricus Laxmann, 1769 & Zamba jirkh & KU527905 \\
\hline MGL-18 & Tamias sibiricus Laxmann, 1769 & Zamba jirkh & KU527906 \\
\hline MGL-88 & Tamias sibiricus, Laxmann, 1769 & Zamba jirkh & KX859266 \\
\hline MGL-19 & Urocitellus undulatus Pallas., 1777 & Urtsuult zuram & KU527907 \\
\hline MGL-63 & Urocitellus undulatus Pallas., 1777 & Urtsuult zuram & KX859256 \\
\hline MGL-64 & Urocitellus undulatus Pallas., 1777 & Urtsuult zuram & KX859257 \\
\hline MGL-20 & Urocitellus undulatus, Pallas.,1777 & Urtsuult zuram & KU527908 \\
\hline MGL-96 & Spermophilus pallidcauda Brandt,1841 & Bozlog zuram & KX859270 \\
\hline MGL-61 & Marmota sibirica, Raddle, 1862 & Mongol tarbaga & KX859254 \\
\hline MGL-21 & Marmota sibirica, Raddle, 1862 & Mongol tarbaga & KU527909 \\
\hline MGL-94 & Marmota sibirica, Raddle, 1862 & Mongol tarbaga & KX859268 \\
\hline MGL-62 & Marmota baibacina, Kastscheno, 1899 & Altain tarbaga & KX859255 \\
\hline
\end{tabular}




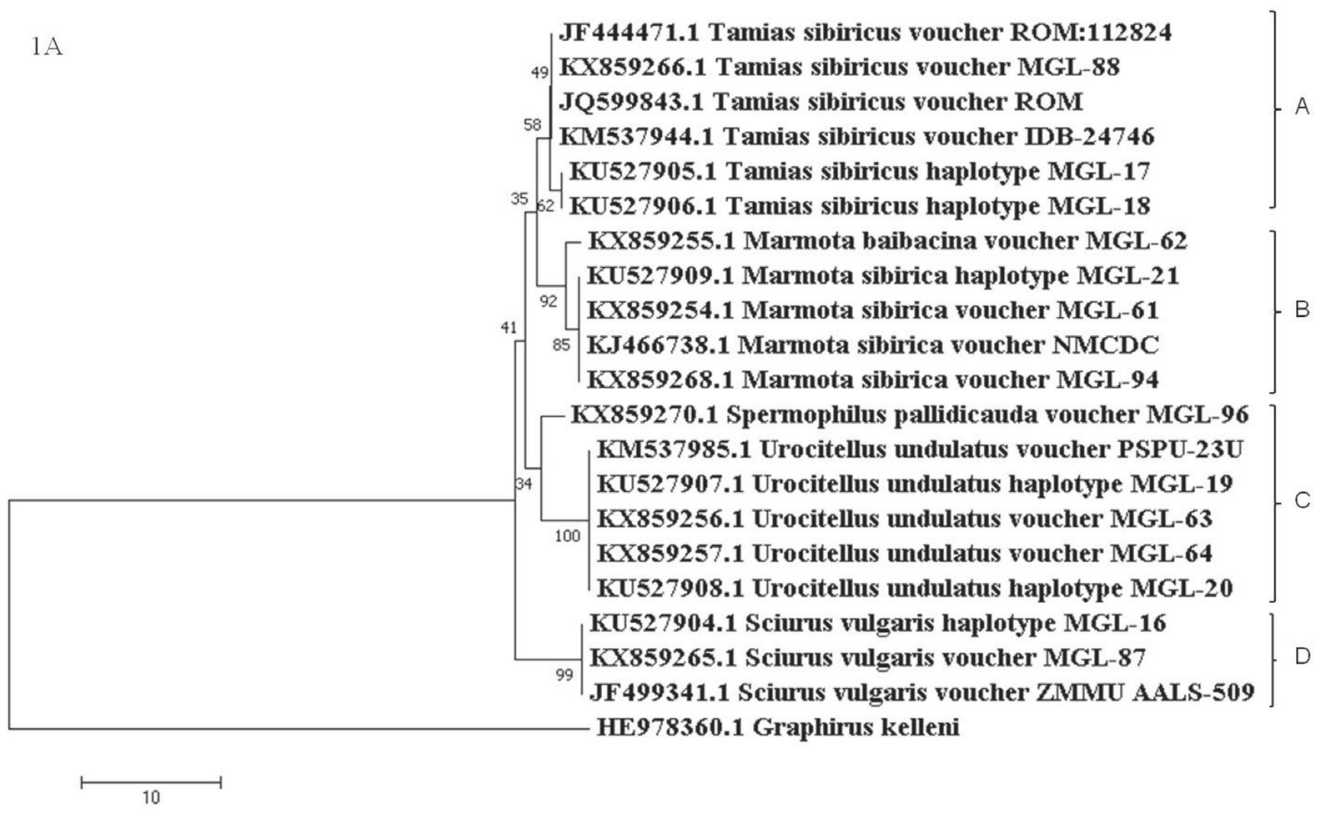

$1 \mathrm{~B}$

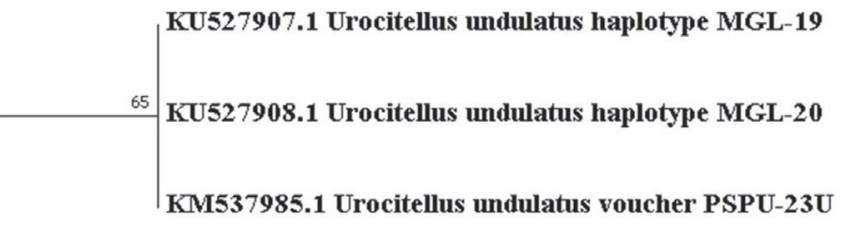

KX859256.1 Urocitellus undulatus voucher MGL-63

KX859257.1 Urocitellus undulatus voucher MGL-64

Figure 1A. Neighbor-joining tree of Sciuridae family as inferred with COI gene sequences of 20 specimens consisting of Tamias (A), Marmota (B), Spermophilus(C) and Sciurus(D). 6 of them were taken from the GeneBank and the remaining 14 were obtained in this study. Neighbor-joining tree was constructed with 1000 boot-strapped replication. Genetic distances were calculated by the Neighbor-joining method. $1 B$.

Neighbor-joining tree of ground squirrel (Spermophilus and Urocitellus)

Acknowledgement: This research has been conducted within the framework of the Higher Education Reform project funded by the Asian Development Bank. We deeply acknowledge the Ministry of Education, Culture, Science and Sports of Mongolia, the Asian Development Bank, and the Higher Education Reform project unit for their support. 


\section{REFERENCES}

[1] Herron, M. D., Castoe, T. A., Parkinson, C. L. "Sciurid phylogeny and the paraphyly of Holarctic ground squirrels (Spermophilus)", Mol Phylogenet Evol. 31(3):1015-30, 2004

[2] Kapustina, S.Yu., Brandler, O.V. and Adiya,Ya., "Phylogeny of genus Spermophilus and position of alashan ground squirrel (Spermophilusalashanicus, Büchner, 1888) on phylogenetic tree of Paleartic short tailed ground squirrels", Molecular Biology, 49:3, 391-396, 2015

[3] Kartavtsev Luf and Lee, J.S., "Analysis of nucleotide diversity at the cytochrome b and cytochrome oxidase 1 genes at the population, species, and genus levels", Genetika 42(4):437-61, 2006

[4] Koh, H. S., Zhang, M., Bayarlhagva, D., Ham, E. J., Kim, J. S., Jang, K. H., Park, N. J., "Concordant genetic distinctness of the phylogroup of the Siberian chipmunk from the Korean Peninsula (Tamais sibiricus barberi), re-examined with nuclear DNA c-myc gene exon 2 and mtDNA control region sequences", Biochem Genet 48:696-705, 2010

[5] Korablev, V. P., Tsvirka, M.V., Chelomina, G. N., Lyapunova, E. A., "Hybridization between Paletailed (Spermophilus pallidicauda Satunin, 1903) and alaschanic (S. Alaschanicus Buchner, 1888) ground squirrels in Mongolia”, Bulletin Moscow Society of Naturalists, Biological section V. 111:5. 26-30, 2006

[6] Kumar, S., Stecher, G., and Tamura, K., MEGA7: Molecular evolutionary genetics analysis version 7.0 for bigger data sets, Molecular Biology and Evolution 33:1870-1874, 2016

[7] Piaggio, A.J. and Spicer, G.S., "Molecular phylogeny of the chipmunks inferred from mitochondrial cytochrome b and cytochrome oxidase II gene sequences", Mol Phylogenet Evol. 20 (3):335-50, 2001

[8] Saitou, N. and Nei, M., The neighbor-joining method: A new method for reconstructing phylogenetic trees. Molecular Biology and Evolution 4:406-425, 1987

[9] Steppan, S. J, Storz, B. L., Hoffmann, R. S., "Nuclear DNA phylogeny of the squirrels (Mammalia: Rodentia) and the evolution of arboreality from c-myc and RAG1", Mol Phylogenet Evol. 30(3):703-19. 2004

[10] Tamura, K., Nei, M., and Kumar, S. (2004). "Prospects for inferring very large phylogenies by using the neighbor-joining method". Proceedings of the National Academy of Sciences (USA) 101:11030-11035, 2004

[11] Tsvirka, M.V., Chelomina, G.N., Korablev, V.P., Genetic evidence of hybridization between pale tailed Spermophiluspallidicauda Satunin, 1903 and alashanic S. alaschanicus Buchner, 1888 ground squirrels in Mongolia, Russian Journal of Genetics. 42:4. 421-428, 2006

[12] Van Dusen, H., "Marmota sibirica" (On-line), Animal Diversity Web. Accessed February 22, 2018 at http://animaldiversity.org/accounts/Marmota_sibirica/

[13] The IUCN Red List of Threatened Species, Version 2018-1. <www.iucbredlist.org > 